\title{
Is Cognitive Case Formulation Science or Science Fiction?
}

\author{
Peter J. Bieling, McMaster University and St. Joseph's Healthcare Hamilton \\ Willem Kuyken, University of Exeter
}

\begin{abstract}
As with all systematic models of therapy, cognitive therapy distills a theory to the understanding of particular cases through the case formulation method. This article sets out criteria to evaluate whether cognitive case formulation follows the process of scientific inquiry, and it questions whether the formulation method meets these criteria. In terms of the evidence base for the cognitive theory that underpins cognitive case formulation, the research suggests that although the descriptive elements of cognitive theory are substantiated, the explanatory elements have received less support. In terms of the scientific status of the cognitive case formulation process, current evidence for the reliability of the cognitive case formulation method is modest, at best. There is a striking paucity of research examining the validity of cognitive case formulations or the impact of cognitive case formulation on therapy outcome. Implications for the clinical use of cognitive case formulation within a scientistpractitioner model are discussed, and potential programs of research to evaluate the case formulation method are described.
\end{abstract}

Key words: depression, anxiety, personality disorder, cognitive therapy, case formulation, cognitive models. [Clin Psychol Sci Prac 10:52-69, 2003]

Since the seminal publication of Cognitive Therapy and the Emotional Disorders (A. T. Beck, 1976), cognitive therapy has emerged as one of the most popular and widely taught therapeutic modalities of the last 20 years (Rush \& Beck,

Send correspondence to Peter J. Bieling, Department of Psychology, St. Joseph's Hospital, 50 Charlton Avenue East, Hamilton, Ontario, Canada L8N 4A6. E-mail: pbieling@sjosham.on.ca.
2000), because, in part, of its consistency with the scientistpractitioner model. Although the scientist-practitioner model has been controversial (Albee, 1970; Barlow, 1981; Barlow, Hayes, \& Nelson, 1984; Garfield, 1998; Rice, 1997; Strupp, 1976), it has probably been the dominant model within clinical psychology since the American Psychological Association's (APA) landmark Boulder conference (Raimy, 1950).

A primary reason for the widespread acceptance of cognitive therapy is its concordance with the scientistpractitioner model. For example, in the area of depression several scholarly reviews (Clark \& Beck, 1999; Coyne \& Gotlib, 1983; Haaga, Dyck, \& Ernst, 1991; Kwon \& Oei, 1994; Teasdale, 1983; Whisman, 1993) suggest consistent support for important aspects of the cognitive theory of depression. In addition, numerous therapy outcome studies suggest that for a significant proportion of individuals, cognitive therapy for depression leads to a clinically significant relief of depressive symptoms (see Clark \& Beck; DeRubeis \& Crits-Christoph, 1998; Dobson, 1989; Robinson, Berman, \& Neimeyer, 1990). Similar scholarly reviews suggest support for important aspects of the cognitive theory of anxiety disorders (e.g., Rapee, 1991) and support for cognitive therapy as an efficacious and effective intervention for anxiety disorders (Barlow, Gorman, Shear, \& Woods, 2000; see also DeRubeis \& Crits-Christoph). Finally, there is also some support for cognitive theory of personality disorders (see Cottraux \& Blackburn, 2001). Although it is premature to judge the efficacy or effectiveness of cognitive therapy for personality disorders, preliminary evidence suggests that patients with comorbid Axis I and II disorders respond to cognitive therapy, albeit less favorably than those with Axis I disorders alone (e.g., Kuyken, Kurzer, DeRubeis, Beck, \& Brown, 2001; Mennin \& Heimberg, 2000). 
Table 1. Case formulation: definition, properties, and key elements

\begin{tabular}{lll} 
Definition & Properties & Elements \\
\hline $\begin{array}{l}\text { A provisional map of a person's presenting } \\
\text { problems that describes the territory of the } \\
\text { problems and explains the processes that caused } \\
\text { and maintain the problems }\end{array}$ & $\begin{array}{l}\text { Describes and explains presenting problems in } \\
\text { terms that can be operationalized (cognition, } \\
\text { affect, and behavior) }\end{array}$ & $\begin{array}{l}\text { Description of manifest presenting problems } \\
\text { (in clear, specific, and measurable terms) }\end{array}$ \\
& Is reliable and valid & Developmental history \\
Causal factors (distal and proximal) & Provides guides for intervention & Maintaining factors \\
Is an active and ongoing process, responsive & Guides for intervention &
\end{tabular}

However, within the practice of cognitive therapy, there remains an important weak link. Although cognitive therapy is effective at relieving a variety of symptoms in different disorders in large-scale randomized, controlled clinical trials and effectiveness studies, researchers cannot conclude that cognitive therapy is effective because its statements about etiology and mechanisms of change are correct. That is, cognitive therapy may work well-may even well work well by changing maladaptive beliefs - but some of the key assumptions that underlie the practice of cognitive therapy may be flawed. Yet, to the scientist-practitioner cognitive therapist, individualized case formulation is the heart of evidence-based practice. It occupies a fundamental place in clinical psychology, like the role of diagnosis in psychiatry. The cognitive case formulation literature (e.g., J. S. Beck, 1995; Needleman, 1999; Persons \& Tompkins, 1997) suggests a broad range of claimed benefits for cognitive case formulation. These include the provision of a systematic cognitive theory framework for hypothesizing about a person's presenting problems, individualized cognitive therapy treatment protocols, improved description and understanding of presenting problems (for therapist and client), improved therapeutic alliance, more focused therapeutic interventions, and enhanced treatment outcomes. Surprisingly, we do not know of any review that evaluates these claims. This article evaluates the research evidence to establish whether the use of individualized case formulations in cognitive therapy can be justified. We first outline the case formulation approach and then propose criteria to evaluate its evidence base within the scientist-practitioner model.

\section{THE COGNITIVE CASE FORMULATION APPROACH}

Most established schools of psychotherapy advocate that a person's presenting problems be clearly defined and underlying psychological mechanisms be articulated (Eells, 1997). Case formulation aims to describe a person's pre- senting problems and to use theory to make explanatory inferences about causes and maintaining factors that can inform interventions. Case formulation schemes generally have several shared key elements (Table 1). These schemes include a description of manifest presenting problems, important relevant developmental history, causal factors (distal and proximal), maintaining factors, coping strengths and weaknesses, and guides for intervention. Beyond these elements, a case formulation comprises a set of hypotheses about the underlying mechanisms that link these elements. For example, why does this person have these problems at this time, and what factors are maintaining the problems? In most definitions, case formulation is theoretically grounded while maintaining the "essence" of the presenting problems for a particular individual (e.g., Denman, 1995).

Cognitive case formulation can be defined as a coherent set of explanatory inferences about the factors causing and maintaining a person's presenting problems, inferences derived from the cognitive theory of emotional disorders. In terms of a "here and now" view, this would normally include a statement of the core beliefs, dysfunctional assumptions, and compensatory strategies underpinning the problems, as well as any problematic cognitive styles or behavioral patterns that maintain the person's difficulties. In terms of a developmental view, this would normally include a statement of how distal and proximal developmental information might have led to the development of beliefs, cognitive styles, and compensatory strategies. A complete cognitive case formulation would normally include the presenting problems (in terms of cognition, affect, and behavior), relevant developmental information, hypothesized cognitive mechanisms underpinning the presenting problems, strengths and resources, and implications for intervention. ${ }^{1}$ A cognitive case formulation is emphatically an account of a person's presenting problems, not of the whole person. 
There have been several attempts to provide cognitive theory-based individualized case formulation systems (e.g., J. S. Beck, 1995; Greenberger \& Padesky, 1995; Linehan, 1993; Muran \& Segal, 1992; Persons, 1993) that differ in emphasis in terms of structural elements included and the process of formulating. We will briefly review the Persons (1989, 1993) and J. S. Beck (1995) schemes, before extrapolating a model that cuts across the different cognitive case formulation schemes. The Persons (1989, 1993; Persons \& Tompkins, 1997) system focuses on two levels, overt difficulties and underlying cognitive mechanisms. Overt difficulties map directly onto what has been described as presenting problems (Table 1). Underlying mechanisms refer to an explanation of how the maladaptive cognitive processing, beliefs, and behaviors cause and maintain presenting problems. Persons (1993) stresses the importance of identifying and working with the core beliefs and triggers to render the person less vulnerable. J. S. Beck (1995) has developed a system that uses (a) the developmental history and (b) several prototypical problematic situations to enable the therapist to identify problematic core beliefs, dysfunctional assumptions, and maladaptive compensatory strategies (for a diagrammatic representation, see J. S. Beck, 1995). Developmental experiences, core beliefs, conditional assumptions, and compensatory strategies are related to each other in understandable ways. In brief, adverse developmental experiences (e.g., an intensely and enduringly critical parent) lead to maladaptive core beliefs (e.g., "I am no good"), with subsidiary beliefs (e.g., "If I am upbeat and bubbly at all times, no one will figure out that I am really no good") that are compensated for by a range of behavioral strategies (e.g., "In all my interactions I will try to be as upbeat as possible").

The J. S. Beck and Persons case formulation systems refer to formalized case formulation approaches. It is likely that most cognitive therapists in practice use their own personalized approach to case formulation, although we are aware of no completed research that examines how the method, content, and process of "real world" case formulation differs from formalized systems set out in published work and taught in cognitive therapy training programs.

\section{THE SCIENCE AND PRACTICE OF COGNITIVE THERAPY AND CASE FORMULATION}

Having described cognitive case formulation, we set out some criteria to evaluate the scientific basis of cognitive case formulation. We suggest that criteria can be separated into two approaches: "top-down" and "bottom-up." We call the assumption that a cognitive case formulation should draw primarily on well-validated aspects of cognitive theory "top-down" (i.e., generalizations from theory are applied to particular cases). Like others, we have made the assumption that within the scientist-practitioner model a therapist draws on theory and research that informs practice (Eells, 1997; Denman, 1995; Salkovskis, 2002). As such, "every application of scientific inquiry is based on an inference from hypotheses (which are universal) to single cases, i.e., upon a deduction of singular predictions" (Popper, 1959, p. 64). Within a scientistpractitioner model, each element in the cognitive case formulation should be subjected to the following questions: Are the constructs in cognitive theory that underpin cognitive case formulation substantiated by evidence? And are the relationships between these elements substantiated by evidence? A positive answer to these questions is the basis on which cognitive case formulation schemes are set out (e.g., J. S. Beck, 1995; Persons \& Tompkins, 1997).

Bottom-up criteria relate to the reliable, valid, and functional mapping of a case formulation onto a person's presenting problems. For evaluating the empirical basis of cognitive case formulation this criterion can be broken down into the following bottom-up queries: (a) Can cognitive therapists reliably formulate cases using the cognitive case formulation systems? (b) Are the key constructs in case formulations meaningfully related to the person's presenting problems? (c) Does cognitive case formulation lead to improved treatment and treatment outcomes? (d) Does cognitive formulation provide a fertile framework that can be readily and usefully applied? We begin by briefly reviewing the extensive literature relating to the top-down criteria. Then we examine the literature relating to the bottom-up criteria. Finally, we outline a research agenda for future research into cognitive case formulation.

At the outset the most critical question might be, "Are our questions answerable?"2 By reference to a program of research on the Core Conflictual Relationship Theme (CCRT) case formulation method (Luborsky \& CritsChristoph, 1998), we show how 25 years of research on the CCRT suggests that the CCRT meets many of the criteria we have set out.

A person's description of his or her relationships is used in the CCRT method to infer core themes in relationship 
conflicts (wishes towards the self, wishes towards others, responses from others, and responses from the self). The authors make explicit links to underlying psychodynamic theory and have developed a systematic and transparent scoring methodology (Luborsky \& Crits-Christoph, 1998). In terms of reliability, a recent review of eight studies examining judges' agreement about core relationship themes, found agreement in the moderate-to-good range ( $\kappa=0.6-0.8$; Luborsky \& Diguer, 1998). Reliability was better for some aspects of the CCRT than for others, and more skilled and systematic judges tended to show higher rates of agreement with each other (Luborsky \& Diguer). Evidence of test-retest reliability has been established from the assessment-to-early-treatment phase (Barber, Luborsky, Crits-Christoph, \& Diguer, 1998). In terms of validity, pervasiveness of core conflictual relationship themes have been associated in predicted ways with defensive functioning (Luborsky, Crits-Christoph, \& Alexander, 1990). Furthermore, changes in CCRT pervasiveness have been associated with symptom changes during therapy (CritsChristoph \& Luborsky, 1998), although the size of changes in CCRT pervasiveness was small (especially for wishes) and the size of the association was modest.

In terms of relationship to outcome, accurate interpretations based on CCRT-derived case formulations have been associated with symptom improvements in a study of 43 clients in brief psychodynamic psychotherapy (CritsChristoph, Cooper, \& Luborsky, 1988). A reasonable explanation of these findings is that accurate case formulations can affect outcome, either directly through the choice of highly appropriate interventions, or more indirectly by enhancing the therapeutic relationship. However, the evidence is conflicting, with one study suggesting that accuracy on key elements of the CCRT predicted changes in the relationship (Crits-Christoph, Barber, \& Kurcias, 1993) and another failing to demonstrate this effect (CritsChristoph, Cooper, \& Luborsky, 1988).

In summary, the CCRT appears to be a case formulation method that is reliable, valid, and related to improved outcomes. However, the CCRT development group has undertaken most of the research, and it remains to be seen whether independent research will replicate these findings. Nonetheless, the CCRT method suggests that a systematic and coherent case formulation approach, when used by well-trained and skilled practitioners, can meet the scientific criteria we have set out. We would argue therefore that this brief review of the CCRT suggests the questions we ask of cognitive case formulation are meaningful and answerable.

\section{A TOP-DOWN ANALYSIS OF COGNITIVE CASE FORMULATION: IS CASE FORMULATION UNDERPINNED BY EVIDENCE-BASED THEORY?}

We have elected to examine the evidence base of cognitive case formulation by using several categories of disorders in which a cognitive theory (CT) model is available: depression, anxiety disorders, and personality disorders. ${ }^{3}$ We review the literature relating to the evidence base for the key elements of cognitive case formulation by addressing a series of falsifiable hypotheses relating to the definable and possibly operational factors within formulation (i.e., situation-emotion-thought-behavior cycle, early life events and parenting, core beliefs, and dysfunctional assumptions and compensatory strategies). We will then examine the linkages between each of these components. We begin with the most essential and well-researched component: the situation-emotion-thought-behavior cycle.

\section{Situation-Emotion-Thought-Behavior Cycle}

The cycle of situation-emotion-thought-behavior (SETB) is the most familiar, and perhaps central, feature of the cognitive formulation. The cognitive model takes as its starting point the notion that it is one's interpretation of any event, rather than the event itself, that leads to emotional distress, whether this interpretation is negative affect or anxious arousal (A. T. Beck, Rush, Shaw, \& Emery, 1979; A. T. Beck, Emery, \& Associates, 1985; Clark \& Beck, 1999). What is the empirical status of this assertion in depression, anxiety, and personality disorders?

For depression, at least two sets of reviewers have comprehensively assessed the SETB question separated by a nearly 10-year span (Clark \& Beck, 1999; Haaga, et al., 1991). For the SETB cycle, four hypotheses are particularly relevant for depression: (a) negativity, depression is characterized by the presence of self-referent negative thinking, (b) specificity, depression has a distinct cognitive profile in terms of both content and process, (c) selective-processing, depression is characterized by a processing bias for negative self-referent information, and (d) primacy, negative cognition influences behavior and emotion. For the negativity hypothesis, the large majority of critical studies have supported this notion, using both thought "checklists" and more open-ended inquiries about the content of cognition (A. T. Beck, Brown, Steer, Eidelson, \& Riskind, 1987; 
Dobson \& Shaw, 1986; Hollon, Kendall, \& Lumry, 1986; Ingram, Kendall, Smith, Donnell, \& Ronan, 1987; Whisman, Diaz, \& Luboski, 1993). The specificity hypothesis argues that psychological disorders can be distinguished from one another according to distinct cognitive profiles, and indeed depression does appear to be characterized by negative cognitions when compared to cognition in other disorders (A. T. Beck, Steer, \& Epstein, 1992; Clark, Beck, \& Stewart, 1990; Sanz \& Avia, 1994; Steer, Beck, Clark, \& Beck, 1994). Also, there is good evidence for the selectiveprocessing hypothesis-depressed persons show a bias toward selecting mood-congruent, negative information from the environment - and many studies do suggest that depressed individuals find negative and positive interpretations of ambiguous stimuli equally acceptable, whereas nondepressed individuals prefer positive interpretations (e.g., Crowson \& Cromwell, 1995, Dykman, Abramson, Alloy, \& Hartlage, 1989; Moretti et al., 1996; Weary \& Williams, 1990).

Most critical for formulation, the primacy hypothesis suggests a link between negative thoughts, emotions, and behavior. One research program has illustrated that ruminative, self-focused negative thoughts are systematically related to enduring negative mood, particularly among depressed women (Nolen-Hoeksema, 1991; NolenHoeksema, Morrow, \& Fredrickson, 1993). Other studies attempt to reduce negative thought content to examine the impact of such cognitive change on affect (Persons \& Burns, 1985; Teasdale \& Fennell, 1982). Overall, both types of studies demonstrate a reciprocal link between negative moods and negative thoughts. Depressed individuals also demonstrate negative interpersonal behavior that can be reliably distinguished from that of nondepressed individuals (e.g. Bieling \& Alden, 2001; Coyne, 1976; Gotlib \& Hammen, 1992; Joiner \& Metalsky, 1995). Overall, then, for depression there appears to be consistent evidence for most components of the SETB cycle, including negativity, specificity, selective processing, and primacy.

Models for anxiety disorders emerged somewhat later than the original cognitive theory of depression, so less research is available on the SETB cycle in anxiety disorders. However, cognitive models of the various anxiety disorders, including generalized anxiety disorder, panic disorder, and social phobia, use conceptual-theoretical models that incorporate a cue or situation (e.g., a social situation or an anomalous physical sensation), a cognition (e.g., threat thoughts), emotional and physical reactions (e.g., fear and heart palpitations), and behavior (e.g. avoidance or safety behavior). Supporting such models, a recent review concluded that individuals with panic disorder selectively attend to threat words and uncomfortable physical sensations, and social phobics attend selectively to social threat words (Antony \& Swinson, 2000). Individuals with panic disorder also display explicit and implicit memory biases for threat words and physical sensations (Amir, McNally, Riemann, \& Clements, 1996; Lundh, Czyzykow, \& Öst, 1997; Westling \& Öst, 1993). Social phobics also appear to be better at remembering faces with a negative or critical expression, and are more likely to interpret ambiguous social interactions negatively (Constans, Penn, Ihen, \& Hope, 1999; Gilboa-Schechtman, Freshman, Amir, \& Foa, 1997; Lundh \& Öst, 1996). Overall, this research suggests a coupling of thoughts, emotions, and physical sensations in anxiety.

In personality disorders cognitive models emphasize that SETB processes are rooted in deeper cognitive structures that are central to personality dysfunction (A. T. Beck et al., 1990; Young, 1990). To date, research on the model is limited, perhaps because of the heterogeneity of personality disorders and difficulties with reliable diagnostic schemes (Arntz, 1999). Nonetheless, in one study using a cognitive profile approach, researchers identified a higher proportion of sociotropic thoughts and beliefs in Cluster C patients, especially in dependent personality disorders (Nordahl \& Stiles, 2000). Preliminary research in this area has also supported the cognitive model's prediction that people with particular personality disorders will report specific maladaptive beliefs (Dreessen, Arntz, Hendriks, Keune, \& van den Hout, 1999; Veen \& Arntz, 2000). Although the overall number of studies is small and contains quite heterogeneous personality pathology in different samples, this research has generally supported the presence of personality-related processing biases at the level of automatic thoughts.

\section{Early Life Events, Parenting, and Cognition}

A second central feature of cognitive formulation is the development of a cognitive diathesis. Cognitive theory posits that the "child learns to construe reality through his or her early experiences with the environment, especially with significant others," and that "sometimes, these early experiences lead children to accept attitudes and beliefs that will later prove maladaptive" (A. T. Beck \& Young, 1985, p. 207). This notion, termed developmental cognitive media- 
tion, states that cognitive processes and maladaptive beliefs mediate between developmental risk factors and subsequent onset of depression, anxiety, and personality disorders (Ingram \& Price, 2001). Given that comprehensive and high-quality reviews of these literatures exist (see Ingram and Price), only a brief summary of the evidence base, with some representative studies, will be included here.

There is consistent support that loss in childhood (e.g., Andrews \& Brown, 1995; Bifulco, Brown, \& Harris, 1987; Brown \& Harris, 1978; Harris, Brown, \& Bifulco, 1986), problematic parenting behaviors (e.g., Brewin, FirthCozens, Furnham, \& McManus, 1992; Cohn, Matias, Tronick, Connell, \& Lyons-Ruth, 1986; Field, 1984; Garber, Robinson, \& Valentiner, 1997; Hammen et al., 1995; Parker, 1983; Reinherz, Giaconia, Hauf, Wasserman, \& Silverman, 1999; Tronick \& Gianino, 1986), and childhood sexual abuse (Andrews, Brown, \& Creasey, 1990; Bifulco, Brown, \& Adler, 1991; Lizardi et al., 1995; Rose, Abramson, Hodulik, Harberstadt, \& Leff, 1994) increase the risk for development of depression. However, there have been relatively fewer tests of the developmental cognitive mediation hypothesis. In one study using an undergraduate sample, limited support was found for a mediating relationship of cognitive variables between reports of maladaptive parenting and subsequent depression (Whisman \& McGarvey, 1995). In another study using a youngadolescent sample, self-worth was found to mediate between reports of maternal parenting and depressive symptoms (Garber et al., 1997).

Research on cognitive mediation in anxiety is also limited. In a comprehensive review of this literature, Rapee (1991) concluded that there is a surprising consistency in the research literature suggesting that reports of parental overcontrol are associated with anxiety disorders (e.g., Dumas, LaFreviere, \& Serketich, 1995; Siqueland, Kendall, \& Steinberg, 1996). A more substantive body of research has examined the developmental hypotheses for personality disorders (See Bernstein, Cohen, Skodol, Bezirganian, \& Brook, 1996; Cicchetti \& Cohen, 1995; Geiger \& Crick, 2001; Millon \& Davis, 1995), but, again, the direct evidence for cognitive mediation in these studies is limited.

Support for the notion that early adversity leads to psychopathology, including depression, anxiety disorders, and personality disorders seems clear. However, there is a paucity of research addressing the developmental cognitive mediation hypothesis, leaving the answer to the question of what mechanisms mediate pathways to risk of psychopathology unanswered. To date, only limited innovative work is beginning to address cognitive mechanisms. This work tentatively suggests that maladaptive beliefs about the self and others may emerge early in the development of at-risk children (e.g., Bartholomew \& Horowitz, 1991; Coyne \& Whiffen, 1995; Taylor \& Ingram, 1999). We suggest that there are probably sufficient grounds in the research literature for practitioners to introduce developmental trauma as important antecedents of psychopathology, but the research does not yet support the notion of specific, cognition-based linkages between adversity and the development of specific disorders.

\section{Core Beliefs}

Core beliefs, or schemas, are fundamental to the cognitive theory of depression (A. T. Beck, 1967; Clark \& Beck, 1999), anxiety (A. T. Beck \& Emery, 1985), and personality disorders (A. T. Beck et al., 1990). These deep cognitive structures are described as information-processing constructs that also contain specific content (Clark \& Beck, 1999; Williams, Watts, MacLeod, \& Matthews, 1997). Researchers have used a variety of experimental paradigms to examine core beliefs, including sentence completion and autobiographical memory recall, and, indeed, numerous studies support the notion of nonconscious, or deep, schematic processing in depression and anxiety (Antony \& Swinson, 2000; Teasdale \& Barnard, 1993; Teasdale, Taylor, Cooper, Hayhurst, \& Paykel, 1995). There is also strong evidence that, even between episodes of depression, evidence of potentially depressogenic beliefs can be found by using experimental probes (Ingram et al., 1998; Segal, Gemar, \& Williams, 1999). Overall, there is substantial evidence for the operation of deep cognitive structures in depression, though many specific aspects of these structures, including their content, are not well understood (Clark \& Beck, 1999).

For anxiety the research literature on core beliefs is less well developed. However, it has been argued that anxiety is related fundamentally to activation of a "threat mode" that marshals cognitive resources to minimize risk to the organism (A. T. Beck \& Clark, 1997). Another promising, potentially parallel, line of enquiry known as looming maladaptive style (LMS) has also recently been described (see Riskind, Williams, Gessner, Chrosniak, \& Cortina, 2000, for a detailed exposition). There is a reliable self-report measure of LMS (the LMSQ; Riskind et al., 1992) designed 
to measure expectations about the dynamic progression of threatening situations (Riskind, Kelly, Moore, Harman, \& Gaines, 2000). Overall, the investigation of core beliefs and schemas in anxiety is still developing, and it is difficult to make detailed or comprehensive conclusions.

In personality disorder core beliefs or schemas are viewed as critical to initiating and maintaining psychopathology (A. T. Beck et al., 1990; Pretzer \& Beck, 1996), and two self-report instruments have been developed to assess the presence of these deep cognitive structures. The Young Schema Questionnaire (YSQ; Young, 1990) was developed to assess early maladaptive schemas (EMS), and in one validity study a number of EMSs were more prominent in the students who scored highest on personality disorder pathology (Schmidt, Joiner, Young, \& Telch, 1995). Using a different approach, A. T. Beck and J. S. Beck (1991) have developed the Personality Beliefs Questionnaire (PBQ) based on current Diagnostic and Statistical Manual of Mental Disorders (American Psychiatric Association, 1994) categorizations of personality disorders. Using this measure, several studies suggest that dysfunctional beliefs hypothesized to characterize personality disorders are indeed reported at higher rates among people diagnosed with these personality disorders (Beck et al., 2001; Kuyken et al., 2001). Overall, then, there is some evidence to support the notion of deep cognitive structures in depression, anxiety, and personality disorders, and some instruments are available to examine these constructs. However, researchers are far from having a comprehensive understanding of how such schemas operate and in what circumstances. This kind of knowledge will have to come from carefully conducted experiments and may require the development of entirely new research paradigms that go beyond self-report (Segal \& Swallow, 1994).

\section{Conditional Assumptions}

The issue of conditional assumptions in cognitive formulation has received limited empirical attention in the depression literature and almost none in the anxiety disorders and personality disorders domains. The most comprehensive measure of this aspect of the cognitive model is the Dysfunctional Attitudes Scale (DAS; Weissman \& Beck, 1978), though it is still unclear whether this scale is specific only to depression or might be useful in other disorders. Because of its content, the DAS may also have applications in the anxiety and personality disorders. Nine types of conditional assumptions are reliably measured by the DAS, and based on content, these attitudes may confer vulnerability for a variety of different disorders (A. T. Beck, Brown, Steer, \& Weissman, 1991). For example, in personality disorders one study using the DAS found that the scores of people diagnosed with borderline personality disorder were higher than those of a control group and quite high when compared to norms of people with other diagnoses (O'Leary et al., 1991). However, for all the categories of disorder we chose to examine, there is little other research on the issue of conditional assumptions.

\section{Compensatory Strategies}

Cognitive formulation makes two related hypotheses about coping and compensatory strategies. First, in the presence of stressors, maladaptive use of cognitive and behavioral coping strategies increases the chance of symptom onset or symptoms' worsening. Second, the activation of maladaptive beliefs leads to the use of maladaptive compensatory strategies directed at deactivating the beliefs and reducing the associated negative affect (J. S. Beck, 1995). The issue of cognitive factors leading to maladaptive coping strategies has not yet been addressed in anxiety or personality disorders. Some research is available in depression, however. For example, coping has been found to mediate the relationship between stressful events and symptoms (Coyne, Aldwin, \& Lazarus, 1981; Billings, Cronkite, \& Moos, 1983; Swindle, Cronkite, \& Moos, 1989), conditional beliefs have been associated with perceptions of social support (Kuiper, Olinger, \& Swallow, 1987; Norman, Miller, \& Dow, 1988), and people diagnosed with depression engage in more avoidance coping and less approach coping (Billings \& Moos, 1984, 1985; Billings et al., 1983; Coyne et al., 1981; Kuyken \& Brewin, 1994). Despite these findings, there is little consensus about the connection between specific cognitions and specific coping strategies.

\section{The Relations Between Constructs of the Formulation Model}

Thus far, our review has addressed the main elements of cognitive formulation with the model "cleaved at its joints." We also have addressed what research is available regarding the theorized relationships between adjacent elements of the model as set out in diagrammatic form by J. S. Beck (1995). Our review suggests limited to good support for many of the elements of the formulation when considered in isolation. However, an analysis of higher order questions that seek to link different components across the "joints" of the model is premature. The amount 
of evidence is typically stronger for depression, probably because the cognitive model was originally derived in depression. Considering only depression, we have seen good evidence for the situation-emotion-thought-behavior cycle, deep cognitive structures, and maladaptive compensatory strategies. However, our review also suggests that there is little evidence linking deep cognition to its proposed antecedents, early life events, or its proposed consequences, conditional beliefs, and compensatory strategies. Also, although there is increasingly strong evidence for the existence of deep-level cognition, much less is known about the structure and processes that govern this level of cognition in depression when compared to biases in thinking.

For anxiety, our review suggests that there is considerable evidence for the link between particular cues, anxious thoughts, emotions of fear, and physiological arousal. Less well characterized in anxiety are developmental antecedents, conditional assumptions, and compensation strategies tied to these beliefs. This paucity of research may be a result of the heterogeneity of the anxiety disorders, or the fact that cognitive models for these disorders developed more recently than models for depression. Certainly the notion of a primal threat mode or maladaptive looming style is a promising line of inquiry for understanding deeper levels of cognition in anxiety.

For personality disorders there are many fewer studies that have focused on cognitive factors specifically. Although some measures of personality-related beliefs exist (e.g. YSQ and PBQ), there are few studies using information-processing paradigms to validate the SETB cycle in personality disorders. Some results appear promising, but the heterogeneity of personality disorders will make validation a long and challenging process. Nonetheless, the evidence base appears to be growing, and interest in cognitive formulation and cognitive models of personality disorder is increasing (cf. Arntz, 1999).

Taken together, the elements of our review suggest that at a nomothetic level cognitive theory of depression, anxiety disorders, and personality disorders is supported in many of its descriptive hypotheses, and cognitive models are under-studied in their more difficult-to-operationalize explanatory hypotheses. Thus, in the transfer to the idiographic level, which defines case formulation, it follows that descriptive statements are justifiable, but explanatory statements should be stated as exploratory hypotheses at best.

\section{A BOTTOM-UP ANALYSIS OF COGNITIVE CASE FORMULATION: ARE COGNITIVE CASE FORMULATIONS RELIABLE, VALID, AND POSITIVELY RELATED TO OUTCOME?}

Our second-phase evaluation concerns the bottom-up criteria. Specifically, is the process of case formulation reliable, clinically valid, and related to improved outcomes?

\section{Reliability of Cognitive Case Formulation}

Can cognitive therapists reliably formulate cases by using cognitive case formulation systems? In an early study raters proved $76 \%$ accurate in identifying hypothesized underlying cognitive mechanisms for particular patients that had been selected for study by an independent group of therapists (Beckham, Boyer, Cook, Leber, \& Watkins, 1984). Persons, Mooney, and Padesky (1995) had clinicians identify overt problems and underlying schemas or beliefs. The results suggested generally good agreement among judges in identifying manifest presenting problems but poor agreement in identifying the hypothesized underlying cognitive mechanisms. In a further study Persons and Bertagnolli (1999) attempted to increase reliability by supplying clinicians with a specific set of problem domains (psychiatric symptoms, as well as interpersonal, work, financial, health, housing, and recreational problems) and more formalized assessment of schemas (using anchor points and specific definitions of a variety of schemas). Inter-judge reliabilities in assessing schemas remained poor, ( $\kappa: 0.37$, single judges; 0.72 , averaged across five judges; Persons \& Bertagnolli, 1999). However, greater training was associated with somewhat greater reliability (Persons \& Bertagnolli). In a very recent study use of a highly systematized case formulation method led to considerably higher reliability on some (e.g., core beliefs) but not all inferential aspects (e.g., dysfunctional assumptions) of cognitive case formulation (Fothergill \& Kuyken, 2002). The findings for level of training were inconclusive, with the most experienced therapists showing highest agreement on some key elements (e.g., of the primary core beliefs). However, they were not consistently more reliable than the less experienced groups. Finally, in an atheoretical study of the case formulation method, good agreement was found for the descriptive but not the inferential aspects of case formulation (Eells, Kendjelic, \& Lucas, 1998). These studies suggest that good reliability can be obtained for the descriptive but not the inferential aspects of cognitive case formulation, and that reliability may be improved 
through training and use of more systematic case formulation methods.

It is important to note that judgments and inferences linking a person's presenting problem to a psychological account of the problem are complex and multidetermined. There is a distinguished theoretical and research lineage suggesting that when people are faced with complex decisions they maximize the chance of efficient decision by taking cognitive shortcuts. The short-cut heuristics include halo effects, illusory correlations, framing biases, recency effects, confirmatory biases, and failure to consider normative standards (e.g., Dawes, 1986; Kuhberger, 1998; Meehl, 1954, 1973; Simon, 1957; Spengler \& Strohmer, 1994; Turk \& Salovey, 1988; Wilson, 1996). For example, a clinician who has a hypothesis that a person's depression is underpinned by a "powerlessness" core belief may look only for confirming evidence (confirmatory bias) and see her or his client's difficulties regaining employment as a consequence of this belief (illusory correlation). Clinicians may make these errors so habitually that in cognitive case formulations of identical cases using identical formulation methods it is not possible to accurately establish consensus. It follows from this fact that more systematic and objective case formulation systems should be less prone to these inferential biases, and "true" rates of agreement between clinicians should be observable.

In summary, past studies make plain a method for evaluating the reliability of formulation, and they appear to offer evidence that at least some aspects of the model can be reliably identified by multiple judges. Moreover, there is some evidence that more systematic cognitive case formulation methods lead to greater reliability and appear to improve with training. However, given the methodological constraints, the studies reviewed here are still inadequate tests of the reliability of formulation. Finally, there are two important caveats in establishing the reliability of case formulation. First, it may yet be found that clinicians can reliably complete case formulations; however, this does not mean that they are valid. Furthermore, whether clinicians can reliably formulate a case is quite distinct from whether the constructs relate to each in the hypothesized manner across situations or time. We know of no studies that bear on the reliability of cognitive case formulations across situations or time.

\section{Clinical Validity of Cognitive Case Formulation}

Are the key constructs in case formulations meaningfully related to a person's presenting problems? Our earlier brief review of the CCRT outlined a range of studies examining this question. We know of no evidence that attempts to show hypothesized relationships between the content of a cognitive case formulation and related aspects of psychological-psychiatric functioning in a particular case. In short, there is no evidence to confirm or falsify the validity of cognitive case formulation.

Relationship Between Case Formulation and Treatment Outcome Does cognitive case formulation lead to improved treatment and treatment outcomes? Hayes, Nelson, and Jarrett (1987) have argued that the treatment utility of a case formulation is the cornerstone of its value. We agree that, together with reliability and validity, this criterion should be a primary one whereby case formulation stands or falls. To our knowledge, there is limited evidence linking case formulation with outcome.

One early study compared manualized with individualized marital therapy of distressed couples. In the individualized intervention, only interventions that matched a formulation of the couples' problems were offered. Although both conditions were comparable at termination, individualized treatment led to somewhat improved maintenance of gains at 6-month follow-up (Jacobson et al., 1989). It is worth noting, however, that the distinction between manualized and individualized formulation and treatments is somewhat arbitrary, because many factors confound this distinction (client, therapist, and therapy process variables). Furthermore, there is some evidence that therapists tailor manuals to individuals, even if instructed not to (Schulte, Kunzel, Pepping, \& ShulteBahrenberg, 1992).

Cognitive analytic therapy (Ryle, Leighton, \& Pollock, 1997) involves the therapist and client in writing a joint formulation letter early in therapy. Research using a multiple-baseline, case study approach found no support for the hypothesis that the formulation letter would lead to improvements in the therapeutic alliance and treatment outcomes (Evans \& Parry, 1996). Two linked studies have used a similar single-case series design to establish the effect of case formulation on the therapeutic relationship, beliefs, and symptoms among people with delusions (Chadwick, Williams, \& MacKenzie, in press). It is inter- 
esting that cognitive case formulation did not discernibly affect patients' ratings of the alliance, but did positively influence therapists' ratings of the alliance (Chadwick et al.). Furthermore, case formulation, as an intervention in its own right, did not clearly impact beliefs or symptoms, even though the evidence suggested that successful subsequent restructuring of beliefs led to symptom improvements (Chadwick et al.). Of note, the Chadwick et al. study is limited to people with psychosis, where the efficacy and effectiveness of cognitive therapy are not fully established and treatment approaches are in development. Finally, these studies share the assumption that the formulation should be explicitly shared with the client, whereas this sharing is not necessarily a feature of cognitive therapy. We may use an analogy: A navigator who shares the whole road map with the driver may hinder rather than help the driver to keep on track, because the driver is given information not directly relevant to the current task and the amount of information may be overwhelming.

In summary, there is no compelling evidence linking cognitive case formulation to improved treatment outcomes. Indeed, the only positive benefit, noted in one study, has been improved ratings of the therapeutic alliance by the therapist. Although standardized cognitive formulations have only recently been published and there has been little time to establish the relationship to outcome, this absence of support for what we consider a basic criterion is of considerable concern. However, we would argue that this may reflect a rather simplistic approach to the issues to date. Studies have made the problematic assumption that case formulation might directly impact outcome, rather than indirectly through the selection of appropriate interventions. The Jacobson et al. (1989) study offers some support for the argument that the usefulness of case formulation is in selecting the most appropriate interventions at the most appropriate time. Can cognitive case formulation be expected to have a direct impact on outcome, or, as has been suggested with the CCRT, might cognitive case formulation affect outcome only through the selection of appropriate interventions (Crits-Christoph et al., 1988)?

\section{Usefulness in Practice of an Evidence-Based Cognitive Case Formulation Approach}

How useful in practice is cognitive case formulation? At the nomothetic level cognitive theory and therapy have generated more research than any other psychological treatment. On the other hand, the use of systematic idiographic cognitive formulation is a relatively recent development and, with a few notable exceptions (Fothergill \& Kuyken, 2002; Persons \& Bertagnolli, 1999), has generated almost no research. In terms of clinical practice, it is increasingly accepted as a dictum among cognitive therapy trainers that a comprehensive and valid case formulation is needed to successfully treat a person in distress, even more so when the presenting problems are complex (J. S. Beck, 1995; Needleman, 1999). Indeed, a great deal of time and expense is devoted to the training and supervision of novice cognitive therapists in "the art of case formulation." Furthermore, cognitive formulation is increasingly being used in therapy process research and therapy trials. Beyond any doubt, cognitive therapy case formulation shows the promise of meeting the fertility criterion in both practice and research.

In terms of the acceptability and usefulness of cognitive case formulation to clients in cognitive therapy, we know of almost no research. Chadwick et al. (in press) interviewed 11 patients with psychosis who had been treated with cognitive therapy, which included a shared cognitive case formulation. It is interesting that clients reported positive (reassured, encouraged, and hopeful) and negative (saddened, upset, and worried) emotional reactions. The reactions were based on increased understanding and seeing a way forward on the positive side and on increased perceptions of problems as complex and longstanding on the negative side. This suggests that clients may experience cognitive case formulation as useful but may also experience it as unhelpful.

In insolation, the fertility criterion is neither necessary nor sufficient to endorse the use of case formulation, because clinical psychology is littered with examples of highly fertile but ultimately unsubstantiated ideas. However-to use an evolutionary analogy - the "fitness" of an idea will determine its advance. In this sense, the systematic evaluation of the case formulation approach can only contribute to its fitness with respect to a fuller understanding of its explanatory power, clinical application, and acceptability to cognitive therapy providers and consumers.

\section{A RESEARCH AGENDA FOR COGNITIVE CASE FORMULATION}

Although the efficacy and effectiveness of cognitive therapy for patients with a range of Axis I and some Axis II dis- 
orders are established (DeRubeis \& Crits-Cristoph, 1998), an outstanding challenge is to provide an evidence base to the individualized formulations that cognitive therapists use to understand their clients' presenting problems and plan their interventions. For the top-down dimension of evidence-based cognitive case formulation, research is being undertaken that addresses the explanatory elements of cognitive theory of a wide range of disorders. From our review, we suggest that researchers would be served by examining those "top-down" areas in which evidence for the formulation is weak or equivocal. Nomothetic tests of the cognitive model that keep in view not just a specific hypothesis about a particular disorder, but also the general formulation model, will yield the most important advances for both researchers and clinicians. Luckily, research on "top-down" questions emerges almost daily. Thus, the outstanding questions about cognitive theory's ability to explain, as well as describe, a range of emotional disorders will probably be answerable in due course. In stark contrast, there is an urgent need for programmatic research to answer the many outstanding questions relating to the bottom-up dimension of case formulation. That is to say, what is the evidence base for the many claimed benefits of cognitive case formulation? We have identified several foci for this research. The fact that research into the CCRT case formulation method has yielded important advances in our understanding about the brief psychodynamic treatment modality (Luborsky \& Crits-Christoph, 1998) attests to the feasibility of the research program we suggest.

A first wave of exploratory research might usefully develop basic understanding of how practicing cognitive therapists formulate in the real world. For example, how widely is case formulation practiced by cognitive therapists? What form of case formulation is used most often? At what stage in the assessment-intervention process do cognitive therapists derive working formulations, and how are these working formulations revised during ongoing work? What does the application of case formulation look like in practice: Does the therapist hold the map, sharing directions only on an as-needed basis, or is the map as a whole drawn up collaboratively and agreed upon before the therapist and client set off? And what are therapists' views of the role and importance of case formulation in their work? Much is assumed about case formulation in practice (e.g., Needleman, 1999), and this research would enable research-based advances in the profession's understanding. This work could take the form of interviewing practicing cognitive therapists, analyzing transcripts of therapy sessions, or using survey, interview, and qualitative research methods. It is likely that this research will ask more questions than it answers, notably by posing the further question, what factors determine which case formulation approaches are best suited to particular therapeutic contexts, clients, and therapists? The case formulation approach for a minimally trained cognitive therapist working in an assertive outreach service for young men with a first episode of psychosis is likely to be very different from the approach taken by a highly trained therapist working in a specialist outpatient clinic for people with mood difficulties.

There are many outstanding questions about the reliability of cognitive case formulation. Given that the literature is conflicting (e.g., Fothergill \& Kuyken, 2002; Persons \& Bertagnolli, 1999), it will be important to establish under what circumstances cognitive therapists can agree about a case formulation. There are large related research literatures addressing the question of how people make complex decisions and how decision making is affected by a range of situational and individual factors: the person's values, cognitive complexity, and preferred decisionmaking style; and the situation's inherent complexity, risk, and uncertainty. Examining clinical decision-making processes using established theoretical and methodological approaches from the decision-making literature (e.g., Dawes, 1986; Kuhberger, 1998) will shed valuable light on the understanding of how therapists make decisions during the formulation process and when this decision making breaks down. Initial studies might identify to what extent and under what circumstances therapists use various information-processing biases (e.g., framing, confirmatory, and recency). An early example of this work amongst theoretically eclectic counselors showed that counselors who scored lower on a cognitive complexity task were more likely to use problematic short-cut heuristics in their clinical decision making (Spengler \& Strohmer, 1994). Replications and extensions of this sort of study will be of considerable value.

There are obvious ways in which the methodology of existing reliability studies can be improved. Studies to date have used convenience samples rather than fully trained or established cognitive therapists who might have a better understanding of the theoretical concepts at hand and their practical application. Furthermore, a combination of wellcontrolled studies (e.g., Fothergill \& Kuyken, 2002) with 
studies which use the data available to real-world clinicians (namely videos of face-to-face interviews) is likely to enable increases in understanding. Finally, we would recommend that studies incorporate in their design the clinical reality that case formulation is an ongoing process, responsive to new data within and between therapy sessions. Is there evidence of change in therapists' formulations on aspects of the formulation that would require adaptation as new information becomes available? Is there evidence of test-retest reliability on aspects of the case formulation that would be expected to remain constant over time?

The sorts of reliability studies we have suggested pose an additional question: Do certain decision-making heuristics affect the process of therapy? The finding that greater counselor cognitive complexity prevents diagnostic overshadowing (Spengler \& Strohmer, 1994) suggests several plausible case formulation studies. For example, a study might examine whether cognitive therapy for personality disorders is more successful when undertaken by cognitive therapists with greater cognitive complexity. Increased sophistication in therapy process research enables these sorts of questions to be answered by careful examination of transcripts of therapy sessions (to identify when ruptures occur and examine how they are resolved) and session-by-session measurement of changes in presenting problems and general functioning.

A further phase of research is required to establish whether the cognitive case formulation has construct and convergent validity; that is, do cognitive case formulations relate meaningfully to people's problems and the factors underlying these problems? Triangulation methodologies, in which the case formulation is one corner of the triangle, would yield valuable information about whether therapists' case formulations map meaningfully onto a person's problems. Other corners of the triangle might be the client's own formulation; the clinical supervisor's independently derived formulation; the person's diagnostic profile; information derived from standardized measures of cognition, affect, and behavior; and information derived from methods used routinely in cognitive therapy to derive core beliefs (e.g., downward-arrow technique), dysfunctional assumptions (e.g., dysfunctional thought records), and compensatory strategies (e.g., A-B-C analysis; J. S. Beck, 1995). It is also important to establish whether case formulations have predictive validity. A case formulation should enable researchers to make predictions about expected relationships between the formulation and present- ing problems, problems encountered in therapy process and problems that are discussed recurrently in therapy sessions. In short, can the formulation predict what clients will think, feel, or do and what will happen over the course of cognitive therapy?

Perhaps most important, future research should concern itself with the link between formulation and outcome. Studies in this area could examine whether cognitive therapists whose cognitive interventions are based on a solid working formulation achieve better outcomes than therapists who do not use formulation. A related research question would be whether adherence to a high-quality case formulation improves treatment outcome through increased therapeutic focus. A variable of interest in this sort of study might be case complexity, with the working hypothesis that adherence should prove more useful with complex patients. Finally, our review suggests that the research concerning whether aspects of case formulation are associated with better therapeutic relationship has produced conflicting findings both in the CCRT and cognitive therapy literatures. Clearly, further research is required to increase understanding of the relationship between case formulation, the therapeutic alliance, and therapeutic outcome.

Although we have set out several criteria for evaluating cognitive case formulation and have suggested avenues for research, it is important to note that not all criteria must be met for formulation to have value. Formulations may be reliable and valid but have no impact on treatment outcome. In contrast, they may be unreliable and invalid but lead through some alternative mechanism (e.g., increasing therapist self-confidence or enhanced alliance) to improved outcome. The research we have outlined would begin to answer these questions and determine which criteria are ultimately most important. This agenda will enable cognitive therapy research and training programs to include training in evidence-based case formulation.

\section{CONCLUSION}

The cognitive formulation is truly open to investigation with experimental methods because of its level of detail, specificity, and relative simplicity. In reality, the cognitive case formulation is highly interwoven with research into cognitive theory. The formulation method has deep roots in these research programs and likely could not have evolved without this research. Moreover, much of the research completed to test cognitive hypotheses, especially 
work examining cognitive mediation, has direct implications for case formulation.

Our review suggests that, contrary to the claimed benefits of cognitive case formulation, it is not a panacea, and its evidence base is weak at best. Our review suggests instead that it is a promising but currently limited approach to describing and understanding patients' presenting problems. As research has contributed to the creation of the cognitive formulation, the fully articulated formulation now offers a rich and fertile starting point for future research. Researchers who turn their attention to this matter will be contributing to the creation of the first empirically validated and reliable scientist-practitioner approach to understanding and treating depression, anxiety, and personality disorders.

At a more general level research on cognitive formulation, theory, and therapy over more than 30 years provides an exemplar of how several dimensions can be integrated: science and practice, the individual case and general theory, and inductive and deductive methods. Our review has drawn on each of these elements to show that the observation of individual cases (e.g., A. T. Beck, 1963) can lead to theory (e.g., A. T. Beck, 1967) that through extensive scientific testing has proven to be a sound descriptive theory (e.g., Clark \& Beck, 1999; Haaga et al., 1991), and has led to a therapy (A. T. Beck et al., 1979) that is efficacious and effective (e.g., DeRubeis \& Crits-Christoph, 1998). The outstanding challenge is to complete the circle and translate the substantiated elements of cognitive theories into a systematic case formulation that stands up to the criteria of empirical validation and treatment utility.

\section{ACKNOWLEDGMENTS}

We contributed equally to this manuscript and are listed in alphabetical order. We would like to express our appreciation to Aaron T. Beck, Paul Chadwick, David A. F. Haaga, and Zindel Segal for their valuable comments on an earlier draft. The ideas in this article took shape while we were completing postdoctoral fellowships with Aaron T. Beck, and we wish to thank Dr. Beck for his inspiration and guidance during that time and since.

\section{NOTES}

1. A description of the assessment tools used to derive a cognitive case formulation is beyond the remit of this article (see J. S. Beck, 1995; Needleman, 1999).

2. We are grateful to commentators on an earlier draft of this manuscript for posing this question.
3. This review is necessarily brief, in part because several high-quality reviews of this literature are readily available.

\section{REFERENCES}

Albee, G. W. (1970). The uncertain future of clinical psychology. American Psychologist, 25, 1071-1080.

American Psychiatric Association (APA). (1994). Diagnostic and Statistical Manual of Mental Disorders (4th ed.). Washington, DC: Author.

Amir, N., McNally, R. J., Riemann, B. C., \& Clements, C. (1996). Implicit memory bias for threat in panic disorder: Application of the "white noise" paradigm. Behaviour Research and Therapy, 34, 157-162.

Andrews, B., \& Brown, G. W. (1995). Stability and change in low self-esteem: The role of psychological factors. Psychological Medicine, 25, 23-31.

Andrews, B., Brown, G. W., \& Creasey, L. (1990). Intergenerational links between psychiatric disorder in mothers and daughters: The role of parenting experiences. Journal of Child Psychology and Psychiatry, 31, 1115-1129.

Antony, M. M., \& Swinson, R. P. (2000). Phobic disorders and panic in adults. Washington, DC: American Psychological Association.

Arntz, A. (1999). Do personality disorders exist? On the validity of the concept and its cognitive-behavioral formulation and treatment. Behaviour Research and Therapy, 37, 97-134.

Barber, J. P., Luborsky, L., Crits-Christoph, P., \& Diguer, L. (1998). Stability of the CCRT from before psychotherapy starts to the early sessions. In L. Luborsky, \& P. CritsChristoph (Eds.), Understanding transference: The Core Conflictual Relationship Theme Method (2nd ed., pp. 253-260). New York: Basic Books.

Barlow, D. H. (1981). On the relation of clinical research to clinical practice: Current issues, new directions. Journal of Consulting and Clinical Psychology, 49, 147-155.

Barlow, D. H., Gorman, J. M., Shear, M. K., \& Woods, S. W. (2000). Cognitive-behavioral therapy, imipramine, or their combination for panic disorder. Journal of the American Medical Association, 283, 2529-2536.

Barlow, D. H., Hayes, S. C., \& Nelson, R. O. (1984). The scientist-practitioner: Research and accountability in clinical and educational settings. Oxford: Pergamon.

Bartholomew, K., \& Horowitz, L. M. (1991). Attachment styles among young adults: A test of a four category model. Journal of Personality and Social Psychology, 61, 226-244.

Beck, A. T. (1963). Thinking and depression: 1. Idiosyncratic content and cognitive distortions. Archives of General Psychiatry, 9, 324-333.

Beck, A. T. (1967). Depression: Causes and treatment. Philadelphia: University of Pennsylvania Press. 
Beck, A. T. (1976). Cognitive therapy and the emotional disorders. New York: International Universities Press.

Beck, A. T., \& Beck, J. S. (1991). The Personality Belief Questionnaire. [Unpublished assessment instrument]. Bala Cynwyd, PA: Beck Institute for Cognitive Therapy and Research.

Beck A. T., Brown, G., Steer, R. A., Eidelson, J. I., \& Riskind, J. H. (1987). Differentiating anxiety and depression: A test of the cognitive content-specificity hypothesis. Journal of Abnormal Psychology, 96, 179-183.

Beck, A. T., Brown, G., Steer, R. A., \& Weissman, A. N. (1991). Factor analysis of the Dysfunctional Attitude Scale in a clinical population. Psychological Assessment, 3, 478-483.

Beck, A. T., Butler, A. C., Brown, G. K., Dahlsgaard, C. F., Newman, C. F., \& Beck, J. S. (2001). Dysfunctional beliefs discriminate personality disorders. Behaviour Research and Therapy, 39, 1213-1225.

Beck, A. T., \& Clark, D. A. (1997). An information processing model of anxiety: Automatic and strategic processes. Behaviour Research and Therapy, 35, 49-58.

Beck, A. T., Emery, G., \& Associates. (1985). Anxiety disorders and phobias: A cognitive perspective. New York: Basic Books.

Beck, A. T., Freeman, A., \& Associates. (1990). Cognitive therapy of personality disorders. New York: Guilford Press.

Beck, A. T., Rush, A. J., Shaw, B. F., \& Emery, G. (1979). Cognitive therapy of depression. New York: Guilford Press.

Beck, A. T., Steer, R. A., \& Epstein, N. (1992). Self-concept dimensions of clinically depressed and anxious outpatients. Journal of Clinical Psychology, 48, 423-432.

Beck, A. T., \& Young, J. E. (1985). Cognitive therapy of depression. In D. Barlow (Ed.), Clinical handbook of psychological disorders: A step-by-step treatment manual. New York: Guilford Press.

Beck, J. S. (1995). Cognitive therapy: Basics and beyond. New York: Guilford Press.

Beckham, E. E., Boyer, J. L., Cook, J. B., Leber, W. R., \& Watkins, J. (1984, June). Development of instrumentation for process research in cognitive therapy. Paper presented at Society for Psychotherapy Research, Lake Louise, Alberta, Canada.

Bernstein, D. P., Cohen, P., Skodol, A., Bezirganian, S., \& Brook, J. S. (1996). Childhood antecedents of adolescent personality disorders. American Journal of Psychiatry, 153, 907-913.

Bieling, P. J., \& Alden, L. E. (2001). Sociotropy, autonomy, and the interpersonal model of depression: An integration. Cognitive Therapy and Research, 25, 167-184.

Bifulco, A. T., Brown, G. W., \& Adler, Z. (1991). Early sexual abuse and clinical depression in adult life. British Journal of Psychiatry, 159, 115-122.

Bifulco, A. T., Brown, G. W., \& Harris, T. O. (1987). Childhood loss of parent, lack of adequate parental care and adult depression: A replication. Journal of Affective Disorders, 12, 115128.
Billings, A. G., Cronkite, R. C., \& Moos, R. H. (1983). Socialenvironmental factors in unipolar depression: Comparisons of depressed patients and nondepressed controls. Journal of $A b$ normal Psychology, 92, 119-133.

Billings, A. G., \& Moos, R. H. (1984). Coping, stress and social resources among adults with unipolar depression. Journal of Personality and Social Psychology, 46, 877-891.

Billings, A. G., \& Moos, R. H. (1985). Life stressors and social resources affect posttreatment outcomes among depressed patients. Journal of Abnormal Psychology, 94, 140-153.

Brewin, C. R., Firth-Cozens, J., Furnham, A., \& McManus, C. (1992). Self-criticism in adulthood and recalled childhood experience. Journal of Abnormal Psychology, 101, 561-566.

Brown, G. W., \& Harris, T. (1978). Social origins of depression. London: Tavistock.

Chadwick, P., Williams, C., \& Mackenzie, J. (in press). Impact of case formulation in cognitive therapy for psychosis. Behaviour Research \& Therapy.

Cicchetti, D., \& Cohen, D. J. (Eds.). (1995). Developmental psychopathology: Vol. 1. Theory and methods. New York: Wiley.

Clark, D. A, \& Beck, A. T. (with Alford, B. A.). (1999). Scientific foundations of cognitive theory and therapy of depression. Chichester, U.K.: Wiley.

Clark, D. A., Beck, A. T., \& Stewart, B. (1990). Cognitive specificity and positive-negative affectivity: Complementary or contradictory views on anxiety and depression? Journal of $A b$ normal Psychology, 99, 148-155.

Cohn, J. F., Matias, R., Tronick, E. Z., Connell, D., \& LyonsRuth, K. (1986). Face to face interactions of depressed mothers and their infants. In E. Z. Tronick \& T. Field (Eds.), Maternal depression and infant disturbance (New directions for child development, No. 34; pp. 31-45). San Francisco:JosseyBass.

Constans, J. I., Penn, D. L., Ihen, G. H., \& Hope, D. A. (1999). Interpretive biases for ambiguous stimuli in social anxiety. Behaviour Research and Therapy, 37, 643-651.

Cottraux, J. \& Blackburn, I. (2001). Cognitive therapy. In W. J. Livesley (Ed)., Handbook of personality disorders: Theory, research, and treatment (pp. 377-399). New York: Guilford Press.

Coyne, J. C. (1976). Toward an interactional description of depression. Psychiatry, 39, 28-40.

Coyne, J. C., Aldwin, C., and Lazarus, R. S. (1981). Depression and coping in stressful episodes. Journal of Abnormal Psychology, 90, 439-447.

Coyne, J. C., \& Gotlib, I. H. (1983). The role of cognition in depression: A critical appraisal. Psychological Bulletin, 94, 472505.

Coyne, J. C., \& Whiffen, V. E. (1995). Issues in personality as diathesis for depression: The case of sociotropy-dependency and autonomy-self-criticism. Psychological Bulletin, 118, 358378. 
Crits-Christoph, P., Barber, J. P., \& Kurcias, J. S. (1993). The accuracy of therapists' interpretations and the development of the therapeutic alliance. Psychotherapy Research, 3, 25-35.

Crits-Christoph, P., Cooper, A., \& Luborsky, L. (1988). The accuracy of therapists' interpretations and the outcome of dynamic psychotherapy. Journal of Consulting and Clinical Psychology, 56, 490-495.

Crits-Christoph, P., \& Luborsky, L. (1998). Changes in CCRT pervasiveness during psychotherapy. In L. Luborsky, \& P. Crits-Christoph (Eds.), Understanding transference: The Core Conflictual Relationship Theme Method (2nd ed.; pp. 151-164). New York: Basic Books.

Crowson, J. J., \& Cromwell, R. L. (1995). Depressed and normal individuals differ both in selection and in perceived tonal quality of positive-negative messages. Journal of Abnormal Psychology, 104, 305-311.

Dawes, R. M. (1986). Representative thinking in clinical judgment. Clinical Psychology Review, 6, 425-441.

Denman, C. (1995). What is the point of a case formulation? In C. Mace (Ed.), The art and science of assessment in psychotherapy (pp. 167-181). London: Routledge.

DeRubeis, R. J., \& Crits-Christoph, P. (1998). Empirically supported individual and group psychological treatments for adult mental disorders. Journal of Consulting and Clinical Psychology, 66, 37-52.

Dobson, K. S. (1989). A meta-analysis of the efficacy of cognitive therapy for depression. Journal of Consulting and Clinical Psychology, 57, 414-419.

Dobson, K. S., \& Shaw, B. F. (1986). Cognitive assessment with major depressive disorders. Cognitive Therapy and Research, 10, 13-29.

Dreessen, L., Arntz, A., Hendriks, T., Keune, N., \& van den Hout, M. (1999). Avoidant personality disorder and implicit schema-congruent information processing bias: A pilot study with a pragmatic inference task. Behaviour Research \& Therapy, 37, 619-632.

Dumas, J. E., LaFreviere, P. J., \& Serketich, J. W. (1995). Balance of power: A transactional analysis of control in motherchild dyads involving socially competent, aggressive and anxious children. Journal of Abnormal Psychology, 104, 104113.

Dykman, B. M., Abramson, L. Y., Alloy, L. B., \& Hartlage, S. (1989). Processing of ambiguous and unambiguous feedback by depressed and nondepressed college students: Schematic biases and their implications for depressive realism. Journal of Personality and Social Psychology, 56, 431-445.

Eells, T. D. (1997). Handbook of psychotherapy case formulation. New York: Guilford Press.

Eells, T. D., Kendjelic, E. M., \& Lucas, C. P. (1998). What's in a case formulation? Development and use of a content coding manual. Journal of Psychotherapy Practice and Research, 7, 144153.
Evans, J., \& Parry, G. (1996). The impact of reformulation in Cognitive-Analytic Therapy with difficult-to-help clients. Clinical Psychology and Psychotherapy, 3, 109-117.

Field, T. M. (1984). Early interactions between infants and their post-partum mothers. Infants Behavior and Development, 7, 527-532.

Fothergill, C. D., \& Kuyken, W. (2002). Reliability of cognitive case formulation using the J. S. Beck Case Conceptualization Diagram. Manuscript submitted for publication.

Garber, J., Robinson, N. S., \& Valentiner, D. (1997). The relation between parenting and adolescent depression: Self-worth as a mediator. Journal of Adolescent Research, 12, 12-33.

Garfield, S. L. (1998). The future and the scientist-practitioner split. American Psychologist, 53, 1231-1232.

Geiger, T. C., \& Crick, N. R. (2001). A developmental psychopathology perspective on vulnerability to personality disorders. In R. E. Ingram \& J. M. Price (Eds.), Vulnerability to psychopathology (pp. 55-102). New York: Guilford Press.

Gilboa-Schechtman, E., Freshman, M., Amir, N., \& Foa, E. B. (1997, November). Have I seen this face before? Memory for facial expressions in generalized social phobics. Paper presented at the meeting of the Association for Advancement of Behavior Therapy, Miami, Florida.

Gotlib, I. H., \& Hammen, C. L. (1992). Psychological aspects of depression: Toward a cognitive interpersonal integration. Chichester, U.K.: Wiley.

Greenberger, D., \& Padesky, C. A. (1995). Mind over mood: Change how you feel by changing the way you think. New York: Guilford Press.

Haaga, D. A. F., Dyck, M. J., \& Ernst, D. (1991). Empirical status of cognitive theory of depression. Psychological Bulletin, 110, 215-236.

Hammen, C. L., Burge, D, Daley, S. E., Davila, J., Paley, B., \& Rudolph, K. D. (1995). Interpersonal attachment cognitions and prediction of symptomatic responses to interpersonal stress. Journal of Abnormal Psychology, 104, 436-443.

Harris, T., Brown, G. W., \& Bifulco, A. (1986). Loss of parent in childhood and adult psychiatric disorder: The role of lack of adequate parental care. Psychological Medicine, 16, 641-59.

Hayes, S. C., Nelson, R. O., \& Jarrett, R. B. (1987). The treatment utility of assessment: A functional approach to evaluating assessment quality. American Psychologist, 42, 963-974.

Hollon, S. D., Kendall, P. C., \& Lumry, A. (1986). Specificity of depressotypic cognitions in clinical depression. Journal of $A b$ normal Psychology, 95, 52-59.

Ingram, R. E., Kendall, P. C., Smith, T. W., Donnell, C., \& Ronan, K. (1987). Cognitive specificity in emotional disorders. Journal of Personality and Social Psychology, 53, 734-742.

Ingram, R. E., Miranda, J., \& Segal, Z. V. (1998). Cognitive vulnerability to depression. New York: Guilford Press.

Ingram, R. E., \& Price, J. M. (Eds.). (2001). Vulnerability to psychopathology. New York: Guilford Press. 
Jacobson, N. S., Schmaling, K. B., Holtzworth-Munroe, A., Katt, J. L., Wood, L. F., \& Follette, V. M. (1989). Researchstructured vs. clinically flexible versions of social learningbased family therapy. Behaviour Research and Therapy, 27, 173180.

Joiner, T. E., \& Metalsky, G. I. (1995). A prospective study of an integrative interpersonal theory of depression: A naturalistic study of college roommates. Journal of Personality and Social Psychology, 69, 778-788.

Kuhberger, A. (1998). The influece of framing on risky decisions: A meta analysis. Organisational Behaviour and Human Decision Making Processes, 75, 23-55.

Kuiper, N. A., Olinger, L. J., \& Swallow, S. R. (1987). Dysfunctional attitudes, mild depression, views of self, selfconsciousness, and social perceptions. Motivation and Emotion, 11, 379-401.

Kuyken, W., \& Brewin, C. R. (1994). Stress and coping in depressed women. Cognitive Therapy and Research, 18, 403-412.

Kuyken, W., Kurzer, N., DeRubeis, R. J., Beck, A. T., \& Brown, G. K. (2001). Response to cognitive therapy in depression: The role of maladaptive beliefs and personality disorders. Journal of Consulting and Clinical Psychology, 69, 560-566.

Kwon, S., \& Oei, T. P. S. (1994). The roles of two levels of cognitions in the development, maintenance, and treatment of depression. Clinical Psychology Review, 14, 331-358.

Linehan, M. M. (1993). Cognitive-behavioral treatment of borderline personality disorder. New York: Guilford Press.

Lizardi, H., Klein, D. N., Ouimette, P. C., Riso, L. P., Anderson, R. L., \& Donaldson, S. K. (1995). Reports of childhood home environment in early-onset dysthymia and episodic major depression. Journal of Abnormal Psychology, 104, 132-139.

Luborsky, L., \& Crits-Christoph, P. (Eds.). (1998). Understanding transference: The Core Conflictual Relationship Theme Method (2nd ed.). New York: Basic Books.

Luborsky, L., Crits-Christoph, P, \& Alexander, K. (1990). Repressive style and relationship patterns: Three samples inspected. In J. Singer (Ed.), Repression and disassociation: Implications for personality theory, psychopathology and health. Chicago: University of Chicago Press.

Luborsky, L., \& Diguer, L. (1998). The reliability of the CCRT measure: Results from eight samples. In L. Luborsky, \& P. Crits-Christoph (Eds.), Understanding transference: The Core Conflictual Relationship Theme Method (2nd ed.; pp. 97-108). New York: Basic Books.

Lundh, L. G., Czyzykow, S., \& Öst, L G. (1997). (1997). Recognition bias for safe faces in panic disorder with agoraphobia. Behaviour Research and Therapy, 36, 323-337.

Lundh, L. G., \& Ost, L. G. (1996). Recognition bias for critical faces in social phobics. Behaviour Research and Therapy, 34, 787-794.

Meehl, P. E. (1954). Clinical versus statistical prediction. Minneapolis, MN: University of Minnesota Press.
Meehl, P. E. (1973). Why I do not attend case conferences. In P. E. Meehl (Ed.), Psychodiagnosis: Selected papers (pp. 225302). New York: Norton.

Mennin, D. S., \& Heimberg, R. G. (2000). The impact of comorbid mood and personality disorders in the cognitivebehavioral treatment of panic disorder. Clinical Psychology Review, 20, 339-357.

Millon, T., \& Davis, R. D. (1995). The development of personality disorders. In D. Cicchetti \& D. J. Cohen (Eds.), Developmental psychopathology: Vol. 2. Risk, disorder, and adaptation (pp. 633-676). New York: Wiley.

Moretti, M. M., Segal, Z. V., McCann, C. D., Shaw, B. F., Miller, D. T., \& Vella, D. (1996). Self-referent versus other-referent information processing in dysphoric, clinically depressed, and remitted depressed subjects. Personality and Social Psychology Bulletin, 22, 68-80.

Muran, J. C., \& Segal, Z. V. (1992). The development of an idiographic measure of self-schemas: An illustration of the construction and use of self-scenarios. Psychotherapy, 29, 524535.

Needleman, L. D. (1999). Cognitive case conceptualisation: A guidebook for practitioners. Mahwah, NJ: Erlbaum.

Nolen-Hoeksema, S. (1991). Responses to depression and their effects on the duration of depressive episodes. Journal of Abnormal Psychology, 100, 569-582.

Nolen-Hoeksema, S., Morrow, J., \& Fredrickson, B. L. (1993). Response styles and the duration of episodes of depression. Journal of Abnormal Psychology, 102, 20-28.

Nordahl, H. M., \& Stiles, T. C. (2000). The specificity of cognitive personality dimensions in cluster $\mathrm{C}$ personality disorders. Behavioural \& Cognitive Psychotherapy, 28, 235-246.

Norman, W. H., Miller, I. W., \& Dow, M. G. (1988). Characteristics of depressed patients with elevated levels of dysfunctional cognitions. Cognitive Therapy and Research, 12, 39-52.

O'Leary, K. M., Cowdry, R. W., Gardner, D. L., Leibenflut, E., Lucas, P. B., \& deJong Meyer, R. (1991). Dysfunctional attitudes in borderline personality disorder. Journal of Personality Disorders, 5, 233-242.

Parker, G. (1983). Parental "affectionless control” as an antecedent to adult depression: A risk factor delineated. Archives of General Psychiatry, 40, 956-960.

Persons, J. B. (1989). Cognitive therapy in practice: A case formulation approach. New York: Norton.

Persons, J. B. (1993). Case conceptualization in cognitivebehavior therapy. In K. T. Kuehlwein \& H. Rosen (Eds.), Cognitive therapy in action: Evolving innovative practice (pp. 3353). San Francisco: Jossey-Bass.

Persons, J. B., \& Bertagnolli, A. (1999). Inter-rater reliability of cognitive-behavioral case formulations for depression: A replication. Cognitive Therapy and Research, 23, 271-284.

Persons, J. B., \& Burns, D. D. (1985). Mechanisms of action of cognitive therapy: The relative co ntributions of technical and 
interpersonal interventions. Cognitive Therapy and Research, 9, 539-551.

Persons, J. B., Mooney, K. A., \& Padesky, C. A. (1995). Interrater reliability of cognitive behavioral case formulations. Cognitive Therapy and Research, 19, 21-34.

Persons, J. B., \& Tompkins, M. A. (1997). Cognitive behavioral case formulation. In T. Eels (Ed.), Handbook of psychotherapy case formulation (pp. 314-339). New York: Guilford Press.

Popper, K. R. (1959). The logic of scientific discovery. New York: Basic Books.

Pretzer, J. L. \& Beck, A. T. (1996). A cognitive theory of personality disorders. In J. F. Clarkin and M. F. Lenzenweger (Eds.), Major theories of personality disorder (pp. 36-105). New York: Guilford Press.

Raimy, V. (Ed.). (1950). Training in clinical psychology (by the staff of the Conference on Graduate Education in Clinical Psychology held at Boulder, Colorado, August 1949). New York: Prentice Hall.

Rapee, R. M. (1991). Generalized anxiety disorder: A review of clinical features and theoretical concepts. Clinical Psychology Review, 11, 419-440.

Reinherz, H. Z., Giacona, R. M., Hauf, A. M. C., Wasserman, M. S., \& Silverman, A. B. (1999). Major depression in the transition to adulthood: Risks and impairments. Journal of Abnormal Psychology, 108, 500-510.

Rice, C. E. (1997). The scientist-practitioner split and the future of psychology. American Psychologist, 52, 1173-1181.

Riskind, J. H., Kelly, K., Moore, R., Harman, W., \& Gaines, H. (1992). The looming of danger: Does it discriminate focal phobia and general anxiety from depression? Cognitive Therapy and Research, 16, 1-20.

Riskind, J. H., Williams, N. L., Gessner, T. L., Chrosniak, L. D., \& Cortina, J. M. (2000). The looming maladaptive style: Anxiety, danger, and schematic processing. Journal of Personality $\mathcal{E}$ Social Psychology, 79, 837-852.

Robinson, L. A., Berman, J. S., \& Neimeyer, R. A. (1990). Psychotherapy for the treatment of depression: A comprehensive review of controlled outcome research. Psychological Bulletin, 108, 1-20.

Rose, D. T., Abramson, L. Y., Hodulik, C. J., Halberstadt, L., \& Leff, G. (1994). Heterogeneity of cognitive style among depressed inpatients. Journal of Abnormal Psychology, 103, 419429.

Rush, A. J., \& Beck, A. T. (2000). Cognitive therapy. In H. I. Kaplan \& B. J. Sadock (Eds.), Comprehensive textbook of psychiatry (7th ed.). Baltimore, MD: Williams \& Wilkins.

Ryle, A., Leighton, T., \& Pollock, P. (1997). Cognitive analytic therapy and borderline personality disorder: The model and the method. London: Wiley.

Salkovskis, P. M. (2002). Empirically grounded clinical interventions: Cognitive-behavioural therapy progresses through a multi-dimensional approach to clinical science. Behavioural and Cognitive Psychotherapy, 30, 3-9.

Sanz, J., \& Avia, M. D. (1994). Cognitive specificity in social anxiety and depression: Self-statements, self-focused attention, and dysfunctional attitudes. Journal of Social and Cognitive Psychology, 13, 105-137.

Schmidt, N. B., Joiner, T. E., Young, J. E., \& Telch, M. J. (1995). The schema questionnaire: Investigation of psychometric properties and the hierarchical structure of a measure of maladaptive schemas. Cognitive Therapy and Research, 19, 295321.

Schulte, D., Kunzel, R., Pepping, G., \& Shulte-Bahrenberg, T. (1992). Tailor-made versus standardized therapy of phobic patients. Advances in Behavior Research and Therapy, 14, 67-92.

Segal, Z. V., Gemar, M., \& Williams, S. (1999). Differential cognitive response to a mood challenge following successful cognitive therapy or pharmacotherapy for unipolar depression. Journal of Abnormal Psychology, 108, 3-10.

Segal, Z. V., \& Swallow, S. R. (1994). Cognitive assessment of unipolar depression: Measuring products, processes, and structures. Behaviour Research and Therapy, 32, 147-158.

Simon, H. A. (1957). Models of man: Social and rational. New York: Wiley.

Siqueland, L., Kendall, P. C., \& Steinberg, L. (1996). Anxiety in children: Perceived family environments and observed family interaction. Journal of Clinical Child Psychology, 25, 225-237.

Spengler, P. M., \& Strohmer, D. C. (1994). Clinical judgment biases: The moderating roles of counselor cognitive complexity and counselor client preferences. Journal of Counseling Psychology, 1, 8-17.

Steer, R. A., Beck, A. T., Clark, D. A., \& Beck, J. S. (1994). Psychometric properties of the Cognition Checklist with psychiatric outpatients and university students. Psychological Assessment, 6, 67-70.

Strupp, H. H. (1976). Clinical psychology, irrationalism, and the erosion of excellence. American Psychologist, 31, 561-571.

Swindle, R. W., Cronkite, R. C., \& Moos, R. H. (1989). Life stressors, social resources, coping, and the four year course of unipolar depression. Journal of Abnormal Psychology, 98, 468477.

Taylor, L., \& Ingram, R. E. (1999). Cognitive reactivity and depressotypic information processing in children of depressed mothers. Journal of Abnormal Psychology, 108, 202-210.

Teasdale, J. D. (1983). Negative thinking in depression: Cause, effect or reciprocal relationship? Advances in Behaviour Research and Therapy, 5, 3-25.

Teasdale, J. D., \& Barnard, P. J. (1993). Affect, cognition, and change: Remodeling depressive thought. Hove, U.K.: Erlbaum.

Teasdale, J. D., \& Fennell, M. J. V. (1982). Immediate effects on depression of cognitive therapy interventions. Cognitive Therapy and Research, 6, 343-352. 
Teasdale, J. D., Taylor, M. J., Cooper, Z., Hayhurst, H., \& Paykel, E. S. (1995). Depressive thinking: Shifts in construct accessibility or in schematic mental models? Journal of Abnormal Psychology, 104, 500-507.

Tronick, E. Z., \& Gianino, A. (1986). The transmission of maternal disturbance to the infant. In E. Z. Tronick \& T. Field (Eds.), Maternal depression and infant disturbance (New directions for child development, No. 34; pp. 5-12). San Francisco: Jossey-Bass.

Turk, D. C., \& Salovey, P. (Eds.). (1988). Reasoning, inference and judgment in clinical psychology. New York: Free Press.

Veen, G., \& Arntz, A. (2000). Multidimensional dichotomous thinking characterizes borderline personality disorder. Cognitive Therapy \& Research, 24, 23-45.

Weary, G., \& Williams, J. P. (1990). Depressive self-presentation: Beyond self-handicapping. Journal of Personality and Social Psychology, 58, 892-898.

Weissman, A. N., \& Beck, A. T. (1978, November). Development and validation of the Dysfunctional Attitudes Scale: A preliminary investigation. Paper presented at the meeting of the Association for the Advancement of Behavior Therapy, Chicago.

Westling, B. E., \& Öst, L. G. (1993). Relationship between panic attack symptoms and cognitions in panic disorder patients. Journal of Anxiety Disorders, 7, 181-194.
Whisman, M. A. (1993). Mediators and moderators of change in cognitive therapy of depression. Psychological Bulletin, 2, 248265.

Whisman, M. A., Diaz, M. L., \& Luboski, J. A. (1993, November). Cognitive specificity of major depression and generalized anxiety disorder. Paper presented at the annual meeting of the Association for Advancement of Behavior Therapy, Atlanta, GA.

Whisman, M. A., \& McGarvey, A. L. (1995). Attachment, depressotypic cognitions, and dysphoria. Cognitive Therapy and Research, 19, 633-650.

Williams, J. M. G., Watts, F. N., MacLeod, C., \& Matthews, A. (1997). Cognitive psychology and the emotional disorders (2nd ed.). Chichester, U.K.: Wiley.

Wilson, G. T. (1996). Manual-based treatments: The clinical application of research findings. Behaviour Research and Therapy, 34, 295-314.

Young, J. E. (1990). Cognitive therapy for personality disorders: A schema focused approach. Sarasota, FL: Professional Resource Exchange.

Received December 13, 2001; revised April 15, 2002; accepted May 6, 2002. 